\title{
LINEAR SUBJECTIVITY AND THE GRADUAL BREAKDOWN OF DESCARTES' PROOF THAT GOD EXISTS IN THE THIRD MEDITATION
}

Lori Balster

University of Dayton

The Meditations of Descartes have a property almost unique to them which I will call during the course of this paper "linear subjectivity." Linear subjectivity is the manifestation of any argument that is presented as purely a work of its author, drawn only from the perceptions and resources of that author (hence subjective), whose strength lies not in collaboration with the reasonings of others or in the use of empirical supporting evidence, but rather in the author's careful, rational, linear progression from one of his ideas to the next throughout the course of the argument. It is this strategy, both subjective and linear, which Descartes employs throughout his Meditations, and in this paper it is my intention to show that there is a crucial place in the third Meditation, most notably, in which Descartes' otherwise largely successful use of this linear subjectivity suddenly and tragically breaks down, the point at which Descartes fails to convince argumentatively that it was God who put the idea of God in him, and that he did not create the concept himself.

Before the crucial place of breakdown can be sufficiently appreciated, however, it is necessary to acknowledge the special problems that linear subjectivity presents for Descartes-problems that do not trouble other, comparable works - but at the same time acknowledge that for a fair amount of the third Meditation linear subjectivity does allow Descartes to pursue the foundation of trustworthy reasoning he was seeking. The breakdown of the third Meditation therefore is not inherently in the style of argument, but rather in what seems to be Descartes' eventual misapplication of it. If we begin our examination of linear subjectivity by noting how its absence affects comparable philosophical works, we may immediately get a sense of both its advantages and disadvantages for Descartes when he uses it as a central part of the Meditations, especially the third Meditation.

Most philosophical ideas are advanced in media res, in the middle of a line of inquiry. Before the newest treatment of a philosophical idea is proposed, its author pays tribute to some treatment (or treatments) presented 
prior to his own, often actively drawing his own contribution out of the previous work on the idea performed by other thinkers, the tenets of that previous work becoming axiomatic in his new treatment. Socrates, in one instance typical of his style of argument, assumes that some Equal exists before he actually begins a discussion involving equals, and likewise he assumes that equal objects strive to be like this Equal but fail!; Nietzsche borrows at the very least the scope and truth-seeking style of Zoroaster in Thus Spake Zarathrustra, presenting truth as a series of revelations whose original source he does not define or explain 2 ; Spinoza $^{3}$ and Sartre 4 build from the foundations of Descartes; Kant, even in his Groundwork of the Metaphysic of Morals ${ }^{5}$, is subjective but not linear in style, not concerning himself with defining or explaining certain basic concepts of truth provided by his intellect. ${ }^{6}$ All of these philosophers, then, avoid linear subjectivity in the instances noted, avoiding in some way foundational proofs of their reasonings.

There are three major advantages in beginning an argument as they do, with a set of axioms: First, each of their new treatments cannot really be evaluated unless their readers enter immediately into an agreement that the pre-conceived axioms which their works rely upon are true. Because of this necessary initial agreement, the author and reader are already on argumentatively friendly terms. Without this agreement, the reader cannot possibly evaluate the new argument, based as it is-or so she would believe-on false premises. ${ }^{7}$

I Phaedo, Phaedo, trans. G.M.A. Grube (Indianapolis: Hackett, 1977) sect. B.

2 Friedrich Nietzsche, Thus Spake Zarathrustra (New York: Viking Press, 1954).

3 Benedictus de Spinoza, The Principles of Philosophy Demonstrated In The Geometric Manner, ed. and trans. Edward Curley (Princeton: Princeton UP, 1985) sect. I pp. 141-164. 4 Jean-Paul Sartre, Existentialism and Human Emotions (New York: Carol Publishing, 1990) p. 9.

5 Immanuel Kant, Groundwork of the Metaphysic of Morals, ed. and trans. H.J. Paton (New York: Harper and Row, 1956).

6 It is true that Kant begins the Groundwork (the work which illustrates several basic principles of metaphysics Kant uses during later works) with his own subjective stance, but he only presents his arguments after having organized his ideas into categories following his consideration of them, rather than showing step by step, idea to idea, how he has arrived at the principles upon which his arguments have been based. His argument is not presented in a linear fashion, then,and this protects it from the fundamental scrutiny to which Descartes is subjected.

${ }^{7}$ Much as it is impossible to determine the relationship between two triangles in geometry without accepting certain principles of geometry, such as the definition of similarity between triangles: "Two triangles which have three angles of one triangle equal respectively 
Second, if the reader does perceive something to be incorrect about the argument, it is possible that the onus is the original thinker's-having provided, as it were, false foundations for the work of the new author. It is possible that the fault lies with the new author's interpretation of the original thinker's rudimentary principles, but in any case, the new author is protected, perhaps even completely, from a fundamental criticism of his work.

Third, authors who rely in part on another thinker's work avoid the infinitely more difficult task of proving the foundations upon which their arguments are based. By using derivatives of difficult-to-demonstrate fundamental principles, such as derivatives like theorems, corrolaries, or lemmas, or any other tools provided by the science of logic, the majority of philosophical authors essentially deal with the results of Logic, ${ }^{8}$ rather than defining or understanding (at the most basic level) what Logic is in itself. Logic is scrutable, it seems, only unto a certain point: All causal statements depend on the truth of the "if" statement, for instance, the truth or falsity of the logical statement seems readily apparent to those who have understood its principles. Determining the truth of the "if" statement is more difficult than determining the truth or falsity of the logical statement, as the establishment of whether or not there is truth in a statement inevitably depends on a wider range of experiences, such as experiences with vocabulary words, spatial perceptions, the behavior and appearance of external objects, etc.

Determining the specific rational basis of the truth statement itself-a determination which would rest on experiences even less easy to categorize and understand than the relatively concrete world experiences just mentioned-is more difficult still. The experience which allows us to evaluate these constructs is undoubtedly the most inscrutable of experiences, since the Logic which allows for the constructs does not seem to be gathered by direct experience of the outside world but seems to be present innately somehow; we seem to "know," as Descartes states it, that logical statements and all other things we believe to be true must be true because we have perceived, with the very best of our perceptions, that they are "clearly and distinctly" true. ${ }^{9}$ The studying of the foundations of these things,

to the three angles of the other triangle and the ratios between the measures of the corresponding sides all equal are said to be similar."

8 Here, the term "Logic" specifically refers to the set of internal principles which we use to make our world intelligible.

${ }^{9}$ René Descartes, Meditations on First Philosophy In Which The Existence of God And The Distinction of the Soul from the Body Are Deomonstrated, trans. Donald A. Cress (Indianapolis: Hackett, 1979) p. 35. 
the foundations of the things which we usually assume we "know," is a far more difficult task than using those obscure, perhaps unknowable foundations of reason as a background for clearer, unquestionably rational arenas like symbolic logic, simply because these arenas are easier to speak about and demonstrate. If we ask about the basis upon which these principles of logic rest, however, we find ourselves as Descartes does, being asked rather to scrutinize the minds with which we scrutinize, and to struggle in an attempt to connect ourselves with, if not peer into, the mind of God.

All of this has bearing on Descartes' Meditations, most disastrously in the third, for we find that by not beginning his arguments with certain axioms or a set of pre-determined principles as givens, he has stripped his argument of a lot of armor which would normally have protected it throughout the course of his reasoning; he has forfeited the advantages which most other philosophers accept, giving up the benefits of initial reader agreement, extended onus, and protection from the necessity of a fundamental proof. Instead, Descartes places his trust exclusively in linear subjectivity, believing that this strategy will not leave him prostrate in the argumentative battlefield, but will rather allow him to reach a fundamental state of doubt from which he may determine, absolutely, what it is he can know for certain.

Unfortunately, Descartes begins his argument with a sizeable uncertainty. This uncertainty is rooted in an entity he refers to as "the natural light" or "the light of reason." Descartes did not feel there was any unclarity contained in his conception of the light of reason, and in a certain mode of thinking, he was right. It is true he has a "clear and distinct" idea of the light of reason in the sense that he recognized it as an entity separate from other things-specifically, he felt it was the entity which allows each human being to discover truth, and allows him or her to behave rationally in accordance with that knowledge. The light of reason is this special thing, according to Descartes. However, in terms of the ambitious plans he has in the third Meditation, his consideration of the light of reason is nevertheless insufficient. If Descartes had merely referred to the light of reason as a distinct entity, no trouble would have visited his argument. Instead, however, he tries to extrapolate from his definition without having any solid knowledge of the thing he's defined. Specifically, he asserts that the light of reason (or the mind's faculties) contains no element of the body, even though he does not know what does comprise the mind.

He believes that he knows what the light of reason is because he knows what it is not, but this is a peculiar logic that seems suspect: it is the equiva- 
lent of Descartes' pointing to a random man in a crowd and saying he knows this man, simply because he can distinguish this man from a cow, a cart, or a sheep.

Descartes' knowledge of the light of reason is scant, especially from a factual, scientific standpoint, but he claims that an "adequate" knowledge of such a thing is not required; in Objections and Replies he says it is enough "for our knowledge to have sufficient adequacy to let us see that we have not rendered it inadequate by intellectual abstraction." 10 Yet, since he has no facts about the light of reason, he must depend on intellectual abstraction alone to give it its properties: "I understand that mind is something complete...although I deny that anything belongs to it which is contained in the idea of the body. But this could not be unless there were a real distinction between mind and body." II But, nevertheless, the mind and the body seem to always exist in conjunction, or at least they normally coexist. Rather than allowing for the fact that the intermingling of the mind and body is a phenomenon that is not completely understood, a phenomenon which may involve the mind's dependence on the body for its construction and/or sustenance, 12 Descartes gradually cleaves them in two-out of his belief that he had sufficient grasp of their natures to do so. (Linear subjectivity would not allow for any ambiguous element to appear in his argument, so Descartes is involved in a conundrum: either he may choose not to deal with the unknown parts of the light of reason and keep his argument on its linear path, or he may choose to admit the ambiguity of what he knows and ruin the confidence and clarity of his argument. Due to his linear subjective strategy, he chooses the former.) To justify this cleavage, Descartes says in his Reply to Objection VI that "many things are apprehended as a unity, which after a more careful scrutiny shows to be distinct," 13 and although this observation may be true, there is no reason for him to assume that it applies in the case of the mind and the body.

Descartes makes a great faulty assumption that his knowledge of the light of reason is sufficient for him to proceed reliably in his argument

${ }^{10}$ René Descartes, "Reply to Objections IV," The Philosophical Works of Descartes in Two Volumes: Volume II, trans. Elizabeth S. Haldane and G.R.T. Ross (United States: Dover, 1934) p. 98.

11 Ibid; Reply to Objections I, p. 23.

12 This very hypothesis is currently being proposed by Antonio Damasio in his book, Descartes' Error, (New York: Tutnam, 1994).

13 Major Philosophical Works, p. 257. 
during the Meditations. For instance-in a bit of evidence which throws doubt on his assumption-he says in his Reply to Objections $I V$ that "nothing can exist in the mind, insofar as it is a thinking thing, of which it is not conscious" and this is "self-evident," for "there can exist in us no thought of which, at the very moment that it is present in us, we are not conscious." 14 Because of the little Descartes knows about the light of reason, there are no real means by which he could possibly gain this knowledge. If he were having unconscious thoughts, he certainly wouldn't be conscious of it. He has no way of knowing that unconscious thoughts are not happening. Given these limitations, it does not seem correct for Descartes to claim that it is "self-evident" that unconscious thoughts do not happen. Descartes may have an awareness of the light of reason, but he does not therefore have awareness of how the faculty actually works, and this is the whole problem-his not knowing enough about the way the light of reason works to be able to successfully rule out imperceived effects of the body.

Descartes intends to use the light of reason to raise himself out of the pit of absolute doubt during the Meditations, but he leaves its own nature unscrutinized, causing his means of exit from fundamental doubt to do little more than draw him back in. The vagueness of the light of reason seems problematic, even before he has placed himself at the profound level of doubt in the Meditations. Such a vagueness occurs in his earlier exploration of the principles of geometry: As Leonard G. Miller comments, "the natural light [for Descartes] is the light of reason and...this light is cast upon the simples [the simple principles upon which all knowledge-especially mathematical knowledge-is based], thus revealing the necessary relations between them, but the exact manner in which reason inspects its objects and the exact nature of the relations it observes remain obscure."15 It may seem unwise for Descartes to claim a position of absolute doubt and then to leave something as important as the light of reason largely unexamined, if we consider how he is depending on his solid grasp of the light of reason to lead him out of fundamental doubt, into a series of things of which he may be absolutely certain. But due to his unaxiomatic linear subjectivity, this particular haziness seems inevitable: His linear subjectivity begins with a fundamental doubt, which we have previously determined

14 Ibid; p. 115.

15 Leonard G. Miller, "Descartes, Mathematics, and God," Meta-meditations: Studies in Descartes, eds. Alexander Sesonke and Noel Fleming (Belmont: Wadsworth, 1965) p. 457. 
to be the most difficult level to treat adequately, and it seems especially difficult in this case, since part of what should have been included in the fundamental doubt-the light of reason itself - was not explored sufficiently, therefore never really removed from this fundamental doubt. It seems, though, that if Descartes had attempted to directly define the light of reason, his discussion would not have been much improved, given that the concrete, scientific facts about the light of nature in the Seventeenth Century were limited at best. Even modern knowledge would be an inadequate source for the kind of discussion Descartes had in mind. Because of linear subjectivity, however, which uses a position of absolute doubt as its starting point, Descartes cannot accept any degree of open-endedness. He cannot accept the notion that, as Miller has said, "It is simply an unanalyzable fact that there are necessary connections and that we can apprehend them," for accepting this would be introducing an unproved given and would result in a position of less than absolute doubt. 16

Nevertheless, Descartes has to proceed, and in fact does, without a secure understanding of what he means by light of reason. Unfortunately, by not thoroughly examining the light of reason he fails to pin down the fundamental nature of human thinking. Thus, when he tries to eliminate the role of the body in the processes of the mind during the second Meditation, he has introduced into his argument a very real difficulty, for although he has distinguished perceived physical perceptions from mental perceptions, he has also explained so little concerning the nature of mental perception that he has made it impossible to rule out the effect of the body in either the creation of mental perception or in its sustenance. It may be true that Descartes has managed to rule out all the physical influences on the mind which he can perceive, but this does not necessarily rule out those influences of the body upon the mind which he can't perceive. He especially can't rule out the possibility that these effects may exist, and it is this possibility which eventually cripples and with the help of his linear subjective strategy eventually ruins the third Meditation.

There is a considerable question of what role perception and sensation have in the workings of the intellect. Because Descartes is using - and, due to the fundamental nature of his argument, must use-linear subjectivity, he cannot admit these uncertainties into his argument at the outset or, as he surely realized, there would be a very limited argument, certainly not one

16 Ibid.; Ibid. 
clear enough or convincing enough to be accepted on a subjective basis alone. To deal, then, with these ambiguous areas, and to begin his reasoning on more secure grounds, he employs a kind of reductivism early in his discussion of what he can be certain is true, a discussion which occurs a number of years prior to the Meditations, in his Discourse on Method. That this reductivism can be seen in his Discourse is significant because the Discourse is the major argumentative forerunner of the Meditations, and out of it he draws some of the more critical subjective reasoning which he uses to eventually to form the Meditations. His tendency in the Discourse which is pertinent here seems distressing, considering his unfortunately dim idea of the light of reason (a dim idea made damaging to the clarity of his reasoning by the fact that he has stripped himself of argumentative armor as previously discussed), and later proves disastrous especially to the argument about God in the third Meditation. ${ }^{17}$ The basic crippling effect of this reductivism occurs because Descartes reduces his logical possibilities of the body's effect on the mind to one, and he tends to conclude that a given claim in his argument must be true, simply because he cannot imagine how it might be true any other way than how he has conceived it. This is a virus he actually introduces very early in his thinking, as when he says in the Discourse that "I could imagine that I had no body, and that there was no world nor any place that I occupied, but that I could not imagine for a moment that I did not exist" which leads him to believe that "this ego[meaning soul, or mind] by which I am what I am, is entirely distinct from my body...and that even if the body were not, the soul would not cease to be all that it now is." 18 Even though he has demonstrated no grounds, no knowledge secure enough to say that the mind may be considered separate from the body-considering how little he actually knows about the light of reason which allows this mind to operate-, he must nevertheless be excused for reductivism at this point in his argument. At this point the linear subjectivity is working for the benefit of the argument, and that is because Descartes is still adhering rigidly to what he knows to be true from

17 This reductivism is made necessary by the vulnerable subjectivity Descartes uses as his typical argumentative approach, a subjectivity which requires a very straightforward, linear progression to preserve the lucidity of its reasoning and to preserve, as a direct consequence, its plausibility - extremely important if the starting point of the argument is a place as precarious as fundamental doubt.

18 René Descartes, "Discourse on the Method of Rightly Conducting the Reason and Seeking Truth in the Science," Philosophical Essays, trans. and ed. Laurence J. Lafleur (Indianapolis: Liberal Arts Press, 1960) p. 32. 
his clear and distinct perceptions. At this point in his argument, it does not seem that there is any alternative to his admitting the fact that he exists and that, since there seems to be a potential for his ego to separate itself from his body, that they may in fact be separate things. It seems, however, that this "separation" is in all cases somewhat illusory-it is true he can imagine himself without his body, but he has not however really separated himself from his body; he has simply separated himself from all his perceptions of his body - what his eyes see of it, its scent, what he can hear of himself shifting in his chair, or the sounds of his heartbeat, etc. Yet, since this separation is not a real one, it is not entirely possible to discount his body's effect on his mind in ways that are not directly available to his perceptions. The body's imperceived effect on the mind is not an important question in the Discourse or in the first two Meditations, however, because in these Meditations Descartes is only making claims about the body's perceived appearance and effects: namely, that they can be ruled out, separated from the mind (just as they seem to be essentially eliminated during sleep). And when he becomes a reductivist on this matter, it seems reasonable to bear with him, at this point in his linear subjectivity. But, nevertheless, as was mentioned before, the virus has been introduced, and when Descartes in the third Meditation begins to use linear subjectivity to prove parts of his argument that rely on his assessment of reality beyond the perceived effects of the body, then his argument is definitely in dire straits, as his linear subjective style depends on clarity and solid subjective foundations. It is at this point that Descartes begins to use linear subjectivity to prove that God exists, and the reductivism virus he introduced in the beginning of the Discourse (after he introduced two other apparent contagions: the cursory treatment of the light of reason and previously, lack of argumentative armor) finally expresses itself - through the misapplication of linear subjectivity.

Descartes states in his Reply to Objections $I$ that he has "not asked what is the cause of my existence in so far as I consist of mind and body, but have limited myself definitely to my position in so far as I am a thing that thinks," and "for thus I have been able far better to free myself from prejudiced conclusions, to follow the dictates of the light of nature," and, most importantly, he feels that because of the limitations he has placed on his thought experiment he can "affirm with certainty that there is nothing in me of which I am not in some way conscious[italics mine]." $19 \mathrm{His}$ denial

19 Philosophical Works of Descartes, p. 13. 
that there may be unconscious thought is important, especially to the third Meditation, since we must permit into our consideration the possibility that there may be imperceived effects of the body upon the mind, imperceived effects which may have resulted-in ways we are not directly aware ofin our own creation of the idea of God, rather than His placing of the idea in us. Our creative power is undefined: we do not know our bounds, so we cannot say with confidence that the creation of an idea of God lies beyond them.

Since Descartes intended his argument to stand for all time, it seems that any modern evidence we might raise to support the possibility that there may be imperceived effects ought to be admitted into the discussion at hand.

At this time, it has become important to demonstrate that there are some very good reasons for suspecting that there may be imperceived effects of the body upon the mind, ways which cast Descartes' use of linear subjectivity - while examining the origins of his idea of God-into doubt.

The first bits of evidence that the body may have imperceived effects upon the mind come from the observations of the Gestaltists. Their early experiments, especially those of Köhler and Wertheimer, indicated very strongly that the mind will perceive shapes which are not really present: certain arrangements of dots or lines may appear to be triangles, squares, ovals, etc., when no such configurations exist. This tendency of the intellect-bringing forth holistic pictures and patterns from an unorganized collection of perceptions-makes it difficult to rule out the possibility that we may have constructed the notion of God somehow from unorganized, sensual perceptions we pick up around us, a possibility which Descartes vigorously denies in the third Meditation. Gestaltists have recognized, among other things, that "some patterns of stimuli...tend to be naturally (or "spontaneously") organized.20 They further note that "spontaneous organization of pattern" in the mind is "a natural function of the stimulus itself and only minimally related to the past experience of the subject." 21 In other words, the mind seems to naturally impose patterns upon its environment just because it has been given certain perceptions due to that environment. Since we cannot be certain how deeply this tendency to construct meaningful organizations out of a series of otherwise unorganized stimuli is rooted

20 Robert L. Solso, Cognitive Psychology, (Boston: Allyn and Bacon, 1991) p. 90.

21 Ibid.; Ibid. 
in the mind, it does not seem that we may rule out the possibility that we have created an idea of the vast properties of God by piecing together smaller things we perceive and understand, much as people may have once pieced together the night skies they saw in various locations on Earth to form the first idea of an infinite universe. The Gestaltists have not specifically claimed that we do get our idea of God in this way, but their evidence concerning the influences bodily perceptions may have on the mind do not permit us to rule this possibility out, as Descartes did subjectively. When Descartes eliminated this possibility, he at the same stroke provided dubious ground for his third Meditation's proof of the existence of God.

These concerns about the ability of the body to influence the mind, to perhaps perceive more than is actually there, more order, more reality, more scope-which would provide a reason as to why we might have constructed our own idea of God-are not only concerns of psychologists. These effects have also been the concern of those who reason from a purely nonempirical basis. Pyne, in what is perhaps his major philosophical work, comes to his own subjective conclusion that "conciousness affirms that all our intellectual apprehensions are somehow derived from sensation." $22 \mathrm{He}$ refers also to this pertinent quote of St. Thomas: "We must assign on the part of the intellect some power to make things actually intelligible." 23 It is this power, it seems, which Descartes may very well have underestimated, and to a great degree he leaves the issue of it out of the range of his usual scrutiny, a scrutiny much needed for the level of subjectivity he attempts to use in the Meditations. If he could have gained a clearer understanding of the light of reason, or could have at least considered that there may be imperceived effects of the body on the mind, he never would have made the mistake of concluding that God must exist, since he would not have been able to consider his mind as an undoubtedly separate entity from his body: he may be able to clearly and distinctly perceive truth at the level of perceived effects of his body, but he cannot say with confidence anything beyond that, especially about God-he simply doesn't know enough about his own devices.

There are additional pieces of evidence which suggest the considerable effect of the body upon the workings of the mind. This evidence suggests that the perceptions of the body are somehow used as a part of the raw materials which create intellectual understanding.

22 John X. Pyne, The Mind, (Cincinnati: Benzinger Bros., 1926) p. 266.

23 Ibid., p. 270. 
For instance, in the case of Helen Keller, a girl who was born both deaf and blind became able to understand words only because of her teacher's close pairing of the sensation of water with the spelling of the word "water" on her hand; Helen's physical perceptions at the time of her understanding of language were the same as other physical perceptions she had felt before, but at that time the sensations' close pairing somehow resulted in Helen's totally different understanding of the situation. She felt "a misty consciousness of something long forgotten...somehow the mystery of language was revealed to me." 24 This event is one of many which shows the close ties of perception to even those intellectual processes which are beyond raw perception (imperceived effects of the body on the mind, i.e. Helen could not have understood language consciously without the close perceptions she had of the water and the spelling of the word into her hand).

Other evidence that we cannot discount the imperceived effects of the body on the mind, effects that could even provide a source for our idea of God, is contained in the work of Cheves Perky. Perky showed a group of subjects dim images on a screen of an object, such as a banana, while asking them to imagine the object themselves. Most of her subjects denied having seen the dim images on the screen, even after these subjects were debriefed-they were so completely certain that the images they had seen on the screen were only imagined! 25 This finding was later confirmed by S.J. Segal and V. Fusella, and what it seems to demonstrate is the mysterious connection between intellectual perception and raw perception, and how it seems quite impossible to separate with confidence the effects of one from the effects of the other. ${ }^{26}$ Descartes believes that he can have faith in what he perceives clearly and distinctly to be true, and he also believes that he can "know nothing with more certainty" than his mind (and he uses this certainty-as indicated before-as a foundation for his claims in the third Meditation), 27 but because of linear subjectivity and his lack of knowledge concerning the light of nature these things are placed in doubt: it appears from Perky's evidence especially that Descartes is quite mistaken to claim such a certainty, that in fact, we can not only be fooled in what we perceive, but also in what we imagine!

\section{Helen Keller, The Story of My Life, (1902) Ch. 1.}

25 Cheves W. Perky, "An experimental study of imagination," American Journal of Psychology, 21 (1910): 422-452.

26 S.J. Segal and V. Fusella, "Influence of imaged pictures and sounds on detection of visual and auditory signals," Journal of Experimental Psychology, 83 (1970): 458-464.

27 Meditations, p. 30. 
Because it seems reasonable now to consider that there are probably imperceived effects of the body on the mind, and since Descartes' proof that God exists is resting on a reductive approach which stems from his argumentative strategy of linear subjectivity, an approach which relies on his obscure understanding of the light of reason, it seems that some very serious doubts have crept into his proof that God exists in the third Meditation, doubts that remain quite difficult to remove.

Descartes believes that God exists because to him there seems to be no possibility that the idea of "an infinite and independent substance, intelligent and powerful in the highest degree" could have "arisen from myself alone," whereas we have just shown that there is certainly no reason to rule this possibility out, given how we have a mental tendency to construct complex patterns and meaningful wholes, even when given only simple, physical perceptions. ${ }^{28}$ The virus spoken of earlier seems especially to have manifested itself here: since Descartes cannot imagine how he himself may have come up with an idea of God, he concludes reductively that he must not have come up with the idea on his own. However, this reductive approach is based on his lack of secure knowledge concerning the light of nature and is for this reason difficult to accept. It seems, then, that Descartes has clearly misapplied his linear subjectivity.

Descartes' proof of the existence of God in the third Meditation is objectionable for a few broad reasons, therefore, but there are a few smaller conceptions Descartes uses which need to be discussed as well, as they contribute to some of the argument's larger problems.

Descartes' idea of objective reality, for instance, is sufficient for his purposes, but his treatment of it with regards to finite and infinite substances is not really sufficient at all. Descartes says that infinite substances (such as God) contain "more objective reality" in them than "those ideas through which finite substances seem to be exhibited." 29

It sounds quite as though he believes that the idea of God has more content than the idea of something finite, or more size, or more weight. However, it seems that our perceptions of these things are somewhat skewed by the light of reason, in the sense that our most complete ideas of them do not really leave them distinctly more or less than each other as Descartes' reductive analysis (brought forth by his use of linear subjectivity) has made them. Rather, the objects which appear either finite or infinite to us are

28 Meditations, p. 34.

29 Meditations, p. 40. 
actually inscrutable to us after a certain point, simply immeasurable. For example, a goat is a finite thing, and a galaxy is infinite. But if one tries to scrutinize a goat, one will have to go to the microscopic level, then to the atomic, then to the subatomic, then even to the sub-sub atomic, perhaps, and quickly it is discovered that several thousand degrees of magnitude can already be assigned to this simple, finite goat, and how far may it be divided? Descartes says in his Reply to Objections VI that "substance has more reality than accident or mode; and infinite substance has more than finite substance," 30 but it appears that this finite goat may in fact possess infinite properties. Finiteness seems to be a more furtive quality than Descartes allows for in his third Meditation. 31 For Descartes to say a finite thing has less objective reality than something infinite in this Meditation seems no better founded than his idea that the mind can be considered truly separate from the body, and his reductive treatment of each of these topics for the sake of linear subjectivity is malignant to his analysis of both.

Descartes also ignores the possibility of his own creative input (as we have shown, a quite valid possibility) when he claims that there must surely be a greater Being because he perceives some deficiency (an absence of the greatest possible amount of "objective reality") in himself. $32 \mathrm{He}$ assumes that he perceives this deficiency because of some existent standard he is aware of (God) against which he does not measure up. However, the existence of this standard is something that he assumes reductively, largely because he cannot imagine why he would not regard himself as God, unless there should be some real deficiency in him-again, he is disregarding his innate intellectual ability to extend and construct from his raw perceptions of himself and the space around him.33 As Bruce Aune points out, perfection (or omnipotence, or infiniteness, or probably any absolute quality which Descartes assigns to God) may not be an actual, realized state, but may be an arbitrary construction. As he illustrates with the case of the English bulldog, "No actual English bulldog will ever be an absolutely perfect speci-

\section{Philosophical Works of Descartes, p. 56.}

31 Because of the intangible nature of infinity, an ancient conception of Zeno's still seems to be a valid possibility. This conception in particular thwarts Descartes' neat divisions of finite and infinite. Because at each instant a thing has magnitude and thickness, "if there is a plurality, they must be both large and small. So small as to have no magnitude, so large as to be infinite." Zeno's Paradoxes, ed. Wesley C. Salmon (Indianapolis: Bobbs-Merrill, 1970) p. 13.

32 Meditations, p. 48.

33 Ibid.; Ibid. 
men of the breed" and it doesn't follow that an ideal bulldog "exists in some transcendent realm. Human beings have invented the standards for perfection here; we have built up our own idea of bulldog perfection."34

It may be that we have invented the standards by which Descartes judges himself deficient, simply out of our tendency to form mental constructs which allow us to form relationships between things, evaluate things, and group things in a meaningful way. We do these things naturally, evidence suggests, just for the sake of mental organization. One may consider, for instance, how we use the idea of average in this way:

A shipment of marbles is supposed to average a diameter of one centimeter. Now, of course, no marble is going to have a diameter of precisely one centimeter. No marble exists whose diameter is exactly, without error, one centimeter. Although no marble exists with this property, the concept is still useful, for it provides a way of defining, to a relevant approximation, all the succeeding shipments of marbles which will be marketed. The idea of the one centimeter marble is retained, not because such a marble exists, but because it is useful for defining a certain class of marbles. It acts as an imaginary point around which real values may cluster.

Now, if we take all these mental tendencies that we seem to havetendencies to somehow combine physical with intellectual perceptions to form wholeness, meaning, etc. where there wasn't any before, to construct from the tiny bits we are given, then it does not seem too unlikely that, at our deepest level of thought, we may be using this tendency to mentally construct so as to organize in much larger, even more useful ways than in the relatively simple creation of a triangle out of a few lines or an idea of averages. Perhaps we build the idea of infinity from putting together pieces of finiteness (as in the starry sky example earlier), an idea of perfection by piecing together the imperfect states around us, infinite beauty, goodness, strength, etc. all being pieced together from the imperfect states that we know, and then, in what would surely be considered our crowning achievement of imagination, we may form the idea of God as a conglomerate of all the absolute states just mentioned (they are, of course, conglomerates in themselves), a combination of all our ideas like infinity, perfection, and so on into a single, huge organizing sphere-whose nucleus we christen God. 35

34 Bruce Aune, Metaphysics: The Elements (Minneapolis: Minnesota UP, 1985) p. 39.

35 This process is mentioned in Objections $\mathrm{V}$, specifically for the concept of infinity (a concept which later becomes a component of the God idea). P. Gassendi, in his letter to Descartes, says "there is no necessity" for the idea of infinity to come from an infinite substance, "for it can be made, in the way already specified, by composition and amplification." Philosophical Works, p. 165. 
It seems that we are being led to a conclusion like the one presented above, if we break away from the confines of linear subjectivity. We seem to have been led to the idea that all imaginative processes, including those which allow us to imagine God, are simply a natural neurological tendency to construct, just our mental use of known things to make imaginary, useful, and organizational unknowns.

It is true that we are considering much stranger possibilities than those Descartes arrived at, concluding as he did that the God many people believed in did exist. However, because he committed some gradual errors in his argument his proof did not quite hold together as well as he had intended originally. Descartes begins his argument by adopting a position of linear subjectivity. He needs to do this because he wants to start at a level of fundamental doubt like no other philosopher had tried before, so he must rely only on himself for his argument (hence, it is a subjective argument). Because he relies only on himself for his argument and wants to begin the argument at a position of fundamental doubt - taking the reader through idea by idea as he determines his argument-Descartes makes his argument open to a fundamental scrutiny, and consequently places himself in a very precarious position at the beginning of his argument. But he must argue in this fashion, or he 1)cannot reach the level of fundamental doubt he desires and 2)his argument, which lacks support aside from his own perspective, would not be able to proceed linearly in any clear, concise, believable way, which it needs to to survive fundamental scrutiny. His argument is in need of protection, therefore, and so he uses a reductive approach, eliminating the possibility of the body's imperceived effect on the mind. This reductivism would be fine, and this approach would make his argument smoother, more concise, and easier to follow, except he has no grounds for dismissing imperceived effects. In fact, there are many reasons for thinking there are imperceived effects. These effects are important because we don't know what the body's influence on the mind is: we can't be sure how the mind works, so we can't be sure of the capacity of the mind, especially its capacity to create the idea of God. It is true we have doubts on this matter because it is difficult to prove that we have created the idea of God, but evidence suggests that we cannot rule out this possibility. If we had to pick one scenario over the other based only on evidence, it seems more plausible that we did conceive of the idea of God ourselves, rather than not. 